\title{
Is the cross-finger flap a good option at the extensor zone defect?
}

\author{
Yakup Ekinci, $M D^{1,2}$ (D), Kaan Gürbüz, MD1,2 (D) \\ 'Department of Orthopedics and Traumatology, Kayseri City Training and Research Hospital, Kayseri, Turkey \\ ${ }^{2}$ Department of Orthopedics and Traumatology, Kayseri Training and Research Hospital, Kayseri, Turkey
}

Reconstructions of dorsal digital finger injuries with or without tendon defect often cause serious difficulties for surgeons as they also affect the extensor mechanism. Although local, regional, or free flaps may be used in the reconstruction of these defects, the results may not always be satisfactory. Various flaps have been described in the literature that can be used in such injuries. ${ }^{[1-5]}$ Although various flaps have been defined for adequate coverage of dorsal finger defects, these flaps may not result in cosmetic and functional satisfaction due to volume mismatch. ${ }^{[6]}$ In order to minimize the problems of the donor finger, the opposite cross finger is defined as the second, third, fourth, and fifth fingers. It is a good alternative to close defects on the side of the middle and distal phalanx. This method, which is not difficult for the surgeon, may be our first choice to treat such defects $[1,7,8]$ Therefore, in this study, we aimed to evaluate the surgical and clinical outcomes of reversed crossfinger subcutaneous flaps applied to patients with dorsal digital defects.

\footnotetext{
Received: December 23, 2019

Accepted: February 10, 2020

Published online: June 18, 2020
}

Correspondence: Yakup Ekinci, MD. Kayseri Şehir Eğitim ve Araştırma Hastanesi, Ortopedi ve Travmatoloji Kliniği, 4. Kat 38080 Kocasinan, Kayseri, Türkiye.

E-mail: belduya@gmail.com

\section{Doi: $10.5606 /$ ehc. 2020.73030}

This study was orally presented at the International Congress of Occupational Accidents, Hand Injuries, and Amputations which was supported by the Turkish Confederation of Employer Associations and the Microsurgery and Reconstruction Foundation and endorsed by the European Society of Plastic, Reconstructive, and Aesthetic Surgery. April 26-27, 2019 Istanbul, Turkey

Citation: Ekinci Y, Gürbüz K. Is the cross-finger flap a good option at the extensor zone defect? Jt Dis Relat Surg 2020;31(2):267-272.

\section{ABSTRACT}

Objectives: This study aims to evaluate the surgical and clinical outcomes of reversed cross-finger subcutaneous flaps applied to patients with dorsal digital defects.

Patients and methods: Between January 2015 and September

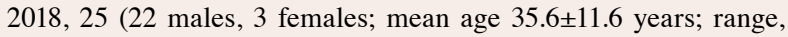
19 to 65 years) out of 27 patients under prospective follow-up with finger dorsal digital defect were retrospectively screened and included in the study. The data, obtained by the same two surgeons at six months postoperatively in patients who had undergone reversed cross-finger subcutaneous flaps surgery, concerned cold intolerance, a static two-point separation test, and functional results using range of motion (ROM) and Quick Disabilities of the Arm, Shoulder and Hand (DASH) scoring.

Results: The majority of the patients presented with occupational injury (64\%), most commonly to the dominant hand (76\%) and the fourth finger (36\%) most frequently. Seven patients with extensor tendon defects underwent reconstruction with a palmaris longus autograft. At the six-week postoperative follow-up, all flaps were live, the donor site had no morbidity, and no additional intervention was performed. There was no statistically significant difference in finger joint ROM $(\mathrm{p}>0.05)$. Cold intolerance was observed in 14 patients $(56 \%)$. The mean dynamic two-point distinction was $6.0 \pm 0.7 \mathrm{~mm}$ and the QuickDASH score was $22.3 \pm 5.0$.

Conclusion: Due to reasons such as minimal donor site morbidity, satisfactory functional finger outcomes, and easy applicability, reversed cross-finger subcutaneous flap is a good option for reconstruction of defects in the dorsal aspect of the finger with or without extensor mechanism defects.

Keywords: Defect, dorsal digital, flap, reversed cross-finger, subcutaneous.

\section{PATIENTS AND METHODS}

This cross-sectional prospective study was conducted at Kayseri Training and Research Hospital and Kayseri City Training and Research Hospital between January 2015 and September 2018. Twenty-seven patients who were admitted to the emergency department with a dorsal finger defect with or without extensor mechanism injury were included in the study. Two patients who did not attend during the follow-up 
period were excluded. Finally, 25 patients ( 22 males, 3 females; mean age $35.6 \pm 11.6$ years; range, 19 to 65 years) were included. The Atasoy technique was applied in all cases. ${ }^{[9]}$ The anesthesia method to be administered was decided by the anesthesiologist. The study protocol was approved by the Erciyes University Clinical Research Ethics Committee (numbered 2019/272). A written informed consent was obtained from each patient. The study was conducted in accordance with the principles of the Declaration of Helsinki.

The patients were evaluated and their age, gender, type of injury, type of anesthesia, location of the defect, skin graft localization, complications, and time to return to work were recorded. At six months postoperatively, Turkish version of the Quick Disabilities of the Arm, Shoulder and Hand (DASH) assessment form was applied and joint range of motion (ROM), cold intolerance, a static two-point separation test for flap sensory examination, and functionality measurements were compared to the opposite side finger of the patients.

Peripheral regional anesthesia and arm tourniquet were used, depending on the patient's condition and the opinion of the anesthesiologist. After routine preparation and draping of the upper extremity, a properly located, sized, and designed flap was marked. The schematic drawing of the surgical technique including flap design and application was presented (Figure 1).

This was usually obliquely located at the dorsum of the middle phalanx about $1 \mathrm{~cm}$ longer and about 4 to $5 \mathrm{~mm}$ wider than the defect. Local debridement was performed on the injured finger (Figure 2a). Then, if the extensor mechanism was involved in the injury, reconstruction of the extensor mechanism with musculus palmaris longus tendon autografting was performed (Figure 2b). Under loupe magnification, a split-thickness skin flap with intact subdermal vascular plexus was elevated based on the opposite side of the uninjured finger (Figure 2c). After full-thickness skin flap elevation on the donor finger, a full-thickness subcutaneous flap under the skin flap was elevated (Figure 2d). Next, the recipient defect was covered with a reversed fullthickness subcutaneous flap (Figure 2e). After reversing the subcutaneous flap with this intact oblique skin island, the skin island was sutured back onto the donor finger. The flap was elevated at the level of the extensor paratenon and the dorsal veins and blood supply were preserved in the flap. After good hemostasis was obtained, the reverse (a)

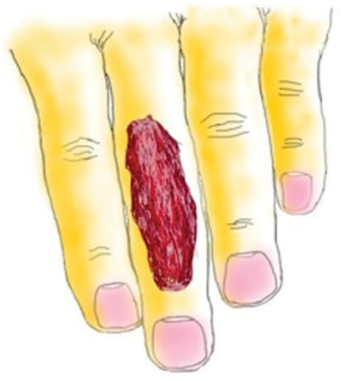

(d)

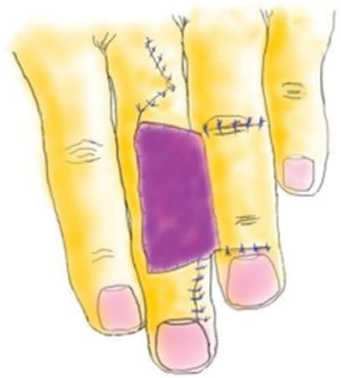

(b)

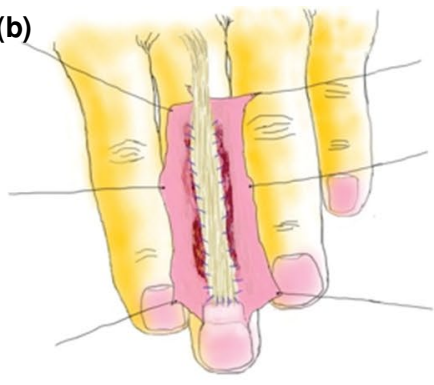

(e)

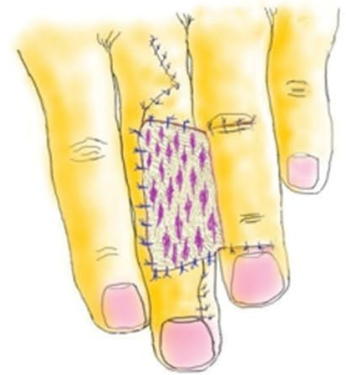

(c)

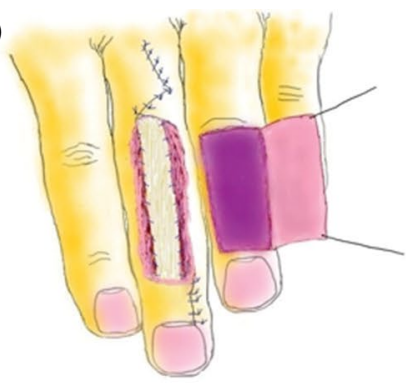

(f)

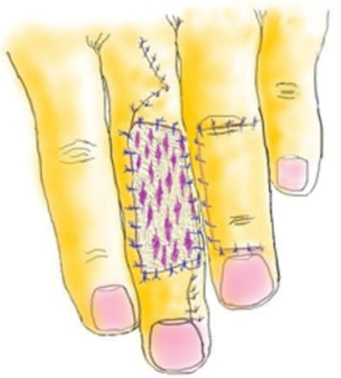

FIGURE 1. Schematic drawing of surgical technique. (a) Dorsal digital defect. (b) Reconstruction of extensor mechanism with musculus palmaris longus tendon autografting. (c) A split-thickness skin flap with intact subdermal vascular plexus elevation. (d) Covering of defect with a reversed full-thickness subcutaneous flap. (e) Covering of reversed full-thickness subcutaneous flap with a split-thickness skin graft. (f) Flap separation. 

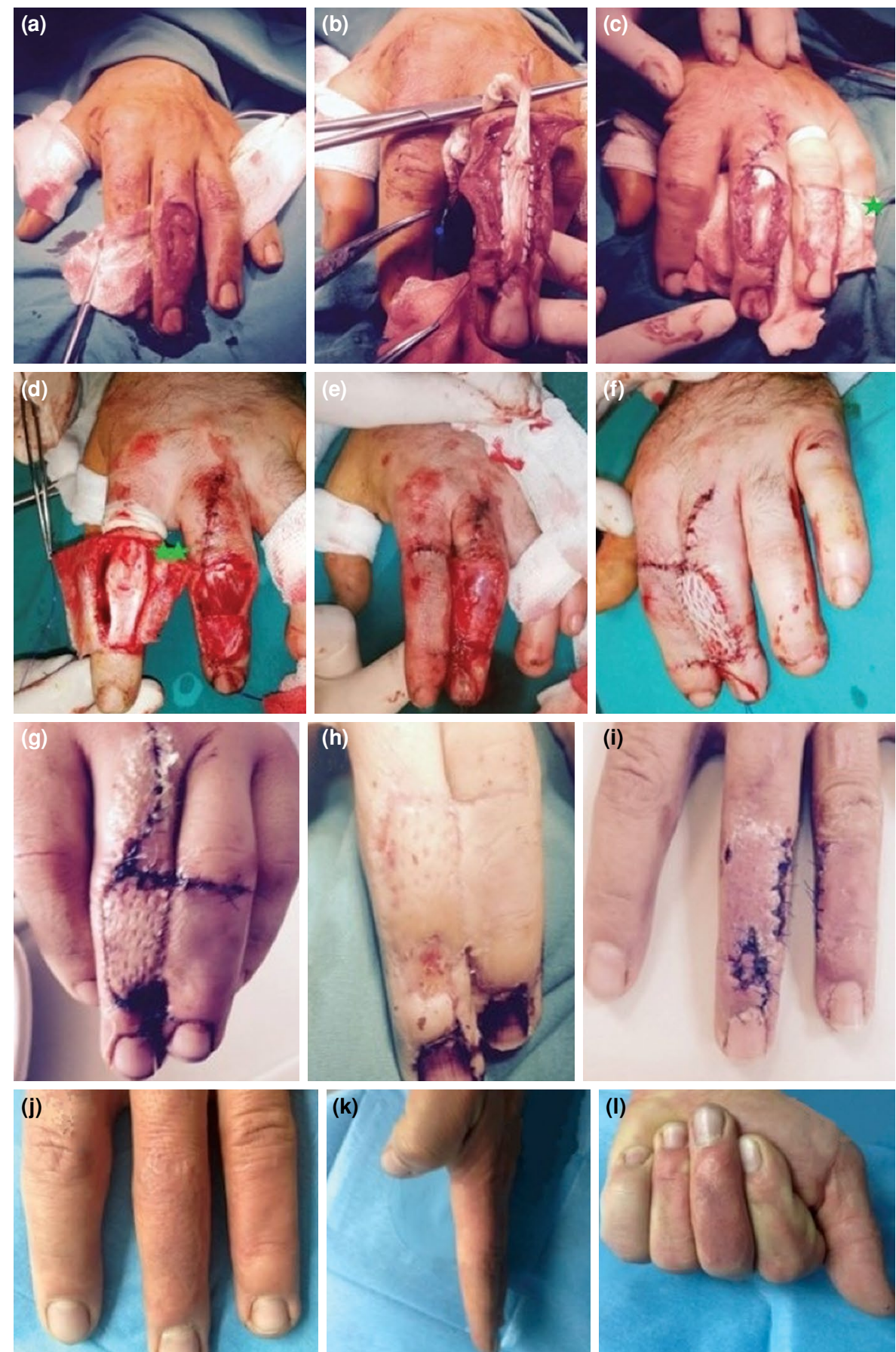

FIGURE 2. Clinical presentation of surgical technique by selected two cases. (a) View of defect including extensor mechanism after surgical debridement. (b) Reconstruction of extensor mechanism with musculus palmaris longus tendon autografting. (c) Elevation of thin full-thickness skin flap at donor finger dorsal side. (d) Elevation of full-thickness subcutaneous flap with an intact skin island. (e) Reversed full-thickness subcutaneous flap covering recipient defect. (f) Skin grafting covering reversed surface of reversed cross-finger subcutaneous flaps. (g) Early postoperative view of donor and recipient fingers after first operation. (h) Preoperative view of donor and recipient fingers before second operation. (i) Early postoperative view of donor and recipient fingers after second operation. (j, $\mathbf{k}$ and $\mathbf{l})$ Final clinical views of donor and recipient fingers at six months.

* Elevated skin flap; ** Elevated and first sutured subcutaneous flap; ${ }^{* \star *}$ All figures show two cases to emphasize steps of surgical technique. 


\begin{tabular}{|c|c|c|}
\hline \multicolumn{3}{|c|}{$\begin{array}{c}\text { TABLE I } \\
\text { Characteristics of patients }\end{array}$} \\
\hline & $\mathrm{n}$ & $\%$ \\
\hline \multicolumn{3}{|l|}{ Gender } \\
\hline Male & 22 & 88 \\
\hline Female & 3 & 12 \\
\hline \multicolumn{3}{|l|}{ Injury type } \\
\hline Industrial accident & 16 & 64 \\
\hline Accident at home & 7 & 28 \\
\hline Traffic accident & 2 & 8 \\
\hline \multicolumn{3}{|l|}{ Localization of injury } \\
\hline Thumb & 1 & 4 \\
\hline Index finger & 7 & 28 \\
\hline Middle finger & 9 & 36 \\
\hline Ring finger & 8 & 32 \\
\hline \multicolumn{3}{|l|}{ Dominant hand } \\
\hline Right & 19 & 76 \\
\hline Left & 6 & 24 \\
\hline \multicolumn{3}{|l|}{ Traumatic hand } \\
\hline Right & 14 & 56 \\
\hline Left & 11 & 44 \\
\hline \multicolumn{3}{|l|}{ Split-thickness skin graft donor site } \\
\hline Upper medial aspect of the humerus & 15 & 60 \\
\hline Groin & 6 & 24 \\
\hline Wrist volar site & 4 & 16 \\
\hline
\end{tabular}

surface of the thin subcutaneous flap on the injured finger was covered with a split-thickness skin graft without a tie-over dressing (Figure 2f). The dressing and sutures were removed in about two weeks (Figures $2 \mathrm{~g}$ and $2 \mathrm{~h}$ ) and the flap between the fingers was divided under local anesthesia in about three weeks (Figure 2i).

After the procedure, a soft dressing was applied to the surgical site. Extremity elevation in a sling is important. All patients started passive physiotherapy just after the second day postoperatively. Active physiotherapy was applied in all patients just two weeks after the second operation.

\section{Statistical analysis}

Statistical evaluations of the data were performed with the IBM SPSS version 22.0 software (IBM Corp., Armonk, NY, USA). The frequency and percentages were given in the evaluation of the data and the relationship analyses were performed using Pearson's chi-square $\left(\chi^{2}\right)$ test. The level of statistical significance was set at a two-sided $p$ value of 0.05 .

\section{RESULTS}

Sixteen of the 25 patients $(64 \%)$ had been involved in industrial accidents and seven $(28 \%)$ in accidents at home, while two $(8 \%)$ were operated on due to traffic

\begin{tabular}{|c|c|c|c|}
\hline \multicolumn{4}{|c|}{$\begin{array}{c}\text { TABLE II } \\
\text { Results of various data }\end{array}$} \\
\hline & $\mathrm{n}$ & Mean \pm SD & Min-Max \\
\hline Time to return to work (days) & 25 & $50.6 \pm 5.6$ & $42-58$ \\
\hline Quick DASH score* & 25 & $22.3 \pm 5.0$ & $15-36$ \\
\hline Two-point discrimination* (mm) & 25 & $6.0 \pm 0.7$ & $5-7$ \\
\hline
\end{tabular}




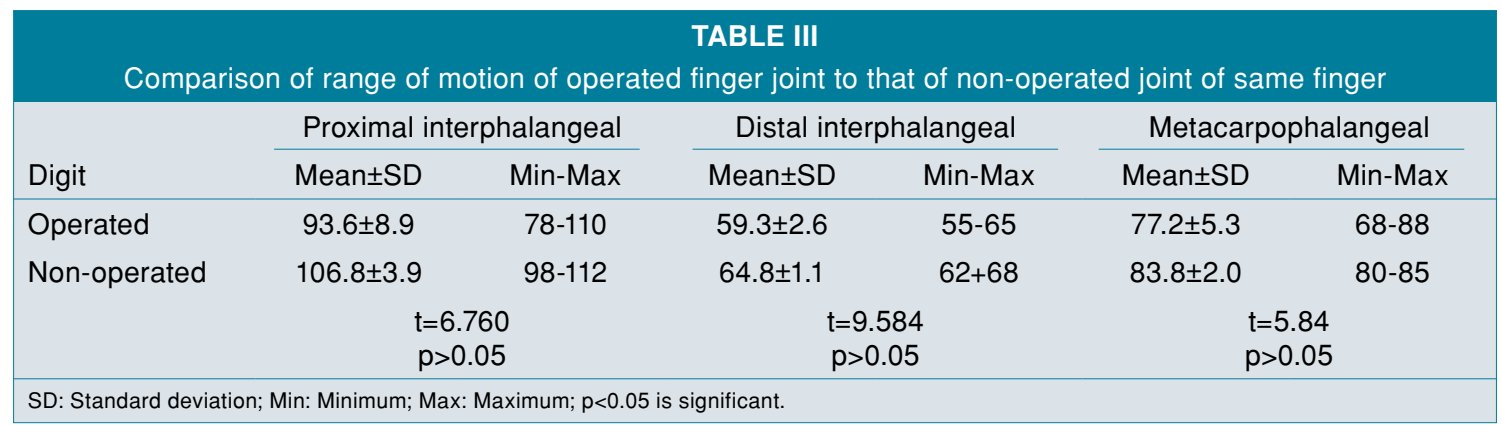

accidents (Table I). The mean duration of return to work was $50.6 \pm 5.6$ days (Table II).

While the right- and left-hand injury rates were balanced $(\mathrm{n}=14,56 \%$ and $\mathrm{n}=11,44 \%)$, the dominant hand was injured more frequently $(\mathrm{n}=18,72 \%)$. The most injured fingers were the fourth finger $(n=9,36 \%)$ and the third finger $(n=8,36 \%)$. Defect sizes ranged from 2 to $4 \mathrm{~cm}^{2}$ (Table I).

Fourteen patients $(56 \%)$ with extensor tendon injuries were treated with primary repair and seven patients (28\%) with the tendon defect were reconstructed with a palmaris longus autograft. Four patients $(16 \%)$ underwent flap treatment without any additional intervention due to a partial defect without functional loss. At the donor site, mostly the skin graft was harvested from the proximal medial face of the arm (15 patients, 60\%) (Table I).

At the six-week postoperative follow-up, all flaps were alive, the donor site had no morbidity, and no additional intervention was performed.

There was no statistically significant difference between the operated finger and the counterpart finger according to proximal interphalangeal, distal interphalangeal, and middle interphalangeal joint ROMs ( $p>0.05$ ) (Table III).

Sixteen patients (56\%) complained of cold intolerance at six months. The dynamic two-point discrimination was $6.0 \pm 0.7 \mathrm{~mm}$ between 5 and $7 \mathrm{~mm}$. The Quick DASH score was $22.3 \pm 5.0$, with the minimum 15 and maximum 36 (Table II).

There were no complications which necessitated a tertiary operation in any case such as partial or total necrosis, early/late or superficial/deep infections.

\section{DISCUSSION}

Reversed cross-finger subcutaneous flaps in dorsal digital defects of the finger were easier to apply than many defined complicated methods, and the clinical outcomes were satisfactory and cost-effective in our study. ${ }^{[10]}$
Although there are many options for treatment, the basic principle is to maintain finger length, provide a sensory skin cover, and functional improvement as much as possible. ${ }^{[11]}$

Treatment options vary depending on many factors. Whether the bone is exposed is one of the most important criteria. If the bone is not exposed, primary suture, split-thickness skin graft, or secondary healing may be used. If the bone is exposed, shortened primary, local, or pedicled flaps or free tissue transfers can be used. ${ }^{[1]]}$ It is possible to repair dorsal defects with a homodigital subcutaneous flap, ${ }^{[1]}$ proximalbased axial digital artery transposition flap, ${ }^{[12]}$ reverseflow digital artery flap, ${ }^{[13]}$ and reversed cross-finger subcutaneous flaps. ${ }^{[7,8,14]}$

Atasoy $^{[3]}$ reported four patients with nail bed defect treated by axial pattern adipofascial flap after the reversed dermis flap described by Pakiam. ${ }^{[2]}$ Voche and Merle ${ }^{[15]}$ described the homodigital subcutaneous flap with axial pattern for the treatment of dorsal finger defects. The most important disadvantages of this application are the fact that the pedicle is distorted after transposition of the flap on the defect and it can cover only two-third of the defect. The axialpatterned adipofascial cross-finger flap described by El-Khatib ${ }^{[16]}$ has the disadvantages of long dissection time and sacrifice of the digital artery. Al-Qattan ${ }^{[14]}$ has modified the existing technique by turning the flap proximally from the same finger.

The reversed cross-finger subcutaneous flaps can be used to treat small to medium-sized dorsal or palmar complicated finger defects at any level. Flap dissection is simple and single level. There are no functional or cosmetic sequelae at the donor site. ${ }^{[17]}$ The application is simple, and the rate of complication development is low. ${ }^{[17]}$ It is highly reliable because it is fed directly from the dorsal segmental branches of the radial or ulnar side of the digital artery. ${ }^{[18]}$ Moreover, the continuity of the digital artery is preserved.

The main disadvantage of the reversed crossfinger subcutaneous flaps is that they require two 
sessions. At 10 to 14 days postoperatively, surgery for separation should be performed. Thus, joint stiffness, which is an important complication, will not be encountered. ${ }^{[19]}$ In our cases, we aimed to separate the flap during this period and to prevent adhesion of the extensor tendon and contraction of the skin graft. At the last follow-up in all cases, the ROM values of the donor and recipient fingers were within normal limits.

In classic cross-finger flaps, two-point separation varies between 3 and $7 \mathrm{~mm} \cdot{ }^{[20]}$ Nicolai and Hentenaar ${ }^{[7]}$ reported that two-point separation was approximately $2 \mathrm{~mm}$ lower in patients under 20 years of age. In our study, this value was $6.01 \mathrm{~mm}$ on average.

Orhun et al. ${ }^{[11]}$ reported cold intolerance in $76.3 \%$ of cases. Nishikawa and Smith ${ }^{[21]}$ reported that $53 \%$ of their patients had cold intolerance and that almost full sensation was achieved in all patients that underwent a sensory examination. In our study, this rate was 56\% and it is compatible with the literature. The results of the QuickDASH scoring were also satisfactory.

Unable to standardize etiological factors is the most important limitation of this study. Another limitation is that the traumatic hand and the dominant hand are not the same sides.

In conclusion, the reversed cross-finger subcutaneous flap is a good option that is satisfactory for the patient and the surgeon to close defects in the dorsal aspect of the finger for various reasons, such as minimal donor site deformity, flexibility, simplicity, ultimately a functional finger, and shorter application time.

\section{Declaration of conflicting interests}

The authors declared no conflicts of interest with respect to the authorship and/or publication of this article.

\section{Funding}

The authors received no financial support for the research and/or authorship of this article.

\section{REFERENCES}

1. Fejjal N, Belmir R, El Mazouz S, Gharib N, Abbassi A, Belmahi A. Reversed cross finger subcutaneous flap: A rapid way to cover finger defects. Indian J Plast Surg 2008;41:55-7.

2. Pakiam AI. The reversed dermis flap. Br J Plast Surg 1978;31:131-5.
3. Atasoy E. Reversed cross-finger subcutaneous flap. J Hand Surg Am 1982;7:481-3.

4. Braga-Silva J, Kuyven CR, Albertoni W, Faloppa F. The adipofascial turn-over flap for coverage of the dorsum of the finger: a modified surgical technique. J Hand Surg Am 2004;29:1038-43.

5. Gurbuz K, Uzun E, Ozan F. Covering the dorsal finger defect with reverse cross finger flap. JCAM 2016;7:262-4.

6. Tark KC, Chung S, Shin KS, Lee YH. Rhomboid design for tubed inguinal flap in fingertip reconstruction. Ann Plast Surg 1996;36:354-9.

7. Lee NH, Pae WS, Roh SG, Oh KJ, Bae CS, Yang KM. Innervated cross-finger pulp flap for reconstruction of the fingertip. Arch Plast Surg 2012;39:637-42.

8. Atasoy E. The Reverse Cross Finger Flap. J Hand Surg Am 2016;41:122-8.

9. Atasoy E. Reversed cross finger subcutaneous tissue flap. In: Strauch B, Vasconez LO, Grabb WC, Hall-Findlay EJ, editors. Grabb's Encyclopedia of Flaps. Vol 2. 1st ed. Boston, MA: Little, Brown and Company; 1990. p. 932-5.

10. Atik OŞ. Which articles do we prefer to publish? Eklem Hastalik Cerrahisi 2018;29:1.

11. Orhun E, Polatkan S, Nuzumlalı E, Kantarcı Ü, Polatkan O. Evaluation of sensory recovery of thenar and cross finger flaps used in finger tip injuries. Acta Orthop Traumatol Turc 2000;34:59-63.

12. Muyldermans T, Hierner R. First dorsal metacarpal artery flap for thumb reconstruction: a retrospective clinical study. Strategies Trauma Limb Reconstr 2009;4:27-33.

13. Kim DH, Seo KB, Lee SH, Lee HJ, Kang HJ. Reverse digital artery cross-finger flap for reconstruction of failed finger replantation. J Orthop Surg (Hong Kong) 2019;27:2309499018816773.

14. Al-Qattan MM. The adipofascial turnover flap for coverage of the exposed distal interphalangeal joint of the fingers and interphalangeal joint of the thumb. J Hand Surg Am 2001;26:1116-9.

15. Voche P, Merle M. The homodigital subcutaneous flap for cover of dorsal finger defects. Br J Plast Surg 1994;47:435-9.

16. El-Khatib H. Adipofascial axial pattern cross-finger flap. Plast Reconstr Surg 1996;97:850-3.

17. Markal Ertaş N, Çelebioğlu S. Cross-Finger Adipofasyal Flep Ile Komplike Parmak Defektlerinin Onarımı. Turkiye Klinikleri J Med Sci 2004;24:153-8.

18. Endo T, Kojima T, Hirase Y. Vascular anatomy of the finger dorsum and a new idea for coverage of the finger pulp defect that restores sensation. J Hand Surg Am 1992;17:927-32.

19. Shao X, Chen C, Zhang X, Yu Y, Ren D, Lu L. Coverage of fingertip defect using a dorsal island pedicle flap including both dorsal digital nerves. J Hand Surg Am 2009;34:1474-81.

20. Papatheodorou LK, Dailiana ZH, Varitimidi SE, Hantes ME, Basdekis GK, Malizos KN. Digital coverage with flaps from the same or neighboring digits. Hippokratia 2011;15:153-6.

21. Nishikawa $H$, Smith PJ. The recovery of sensation and function after cross-finger flaps for fingertip injury. J Hand Surg Br 1992;17:102-7. 